\title{
World Pest Day: Not for Pests, But for People
}

\author{
Jianguo $\mathrm{Xu}^{*}$
}

World Pest Day was inaugurated by the Chinese Pest Control Association and several organizations such as the Federation of Asian and Oceania Pest Managers Associations, the National Pest Management Association of US, Confederation of European Pest Management Associations, World Health Organization (WHO) Collaborating Centre for Vector Surveillance and Management, and State Key Laboratory of Infectious Disease Prevention and Control (China CDC). It was endorsed by 42 academicians from the Chinese Academy of Science and Chinese Academy of Engineering, as well as 21 Members of the National Political Consultative Committee of China. June 6 is reserved annually to raise awareness among the public, government, and media about the important role that the pest control industry plays in protecting health, food, property and the environment from pest threats.

World Pest Day is for the people, not for the pests (1). Globally, more and more vector-borne pathogens have recently emerged (2). The diseases transmitted by mosquitoes, ticks, and rodents have been extensively reported, such as human granulocytic anaplasmosis, dengue (3), new bunia virus, and Jingmen tick-borne virus. More than 5 billion people worldwide are at risk of one or more vector-borne diseases, and over 0.7 million people die annually from these diseases.

Pests are an important factor of reduction in food production and pollution (4). Therefore, the theme of World Pest Day 2018 was "pest control for food safety". Conservative estimations suggest that pests are responsible for an $8 \%-10 \%$ loss of grain stored by farmers and households in China, which may be as much as 1.5-6 million tons.

With the acceleration of globalization, pests are increasingly capable of crossing borders between countries using modern means of transportation. This can have consequences for human and animal health as well as for food safety.

Climate changes, especially the increase in temperature, mean that pests can live longer or no longer die at the same rate due to milder winters (5). In combination with globalization, this creates a risk for mosquitoes to spread across countries and transmit dangerous diseases. Increased urbanization also increases the potential for nuisances from pests such as rodents.

If we want to achieve the grand goal of Healthy China and Healthy World, we must control harmful pests and improve the quality of life (G). We want to keep mosquitoes, rodents, and other pests away from our home and our working and leisure environments at the very least.

Science and technology are eagerly needed to promote pest control practice. Although increasing numbers of advanced products and equipment appear every year, these advances are insufficient and need to be increased.

We need support from governments, academic organizations, the public, media, and industries to spread the concept of scientific pest control, to enhance the professional respect of pest control practitioners, and to call on people to pay attention to pest control activities (G).

Rodents can transmit a variety of diseases and have caused three plague pandemics in history. The year of 2020 is the year of rat in Chinese Lunar Calendar. The theme of World Pest Day 2020 is rodent control for health. We hope that we can take action to jointly control damage caused by rodents and to prevent rodent-borne diseases and protect human health and well-being.

doi: $10.46234 / \mathrm{ccdcw} 2020.110$

\# Corresponding author: Jianguo Xu, xujianguo@icdc.cn.

Submitted: May 13, 2020; Accepted: May 21, 2020

\section{REFERENCES}

1. Chu CK, Sze TS. The patriotic public health campaign--a nation-wide mobilization for health. Chin Med J (Engl) 1978;4(4):253-6. http://www. 
ncbi.nlm.nih.gov/pubmed/100283.

2. Kilpatrick AM, Randolph SE. Drivers, dynamics, and control of emerging vector-borne zoonotic diseases. Lancet 2012;380(9857):1946-55. http://dx.doi.org/10.1016/S0140-6736(12)61151-9.

3. Chen B, Liu QY. Dengue fever in China. Lancet 2015;385(9978):1621 - 2. http://dx.doi.org/10.1016/S0140-6736(15)60793-0.

4. Chiang HC. Pest control in the people's republic of China. Science 1976;192(4240):675-7. http://dx.doi.org/10.1126/science.192.4240. 675.

5. Matzrafi M. Climate change exacerbates pest damage through reduced pesticide efficacy. Pest Manag Sci 2019;75(1):9 - 13. http://dx.doi.org/10.1002/ ps. 5121.

6. Chen PJ, Li FZ, Harmer P. Healthy China 2030: moving from blueprint to action with a new focus on public health. Lancet Public Health $2019 ; 4(9)$ :e447. http://dx.doi.org/10.1016/S2468-2667(19)30160-4.

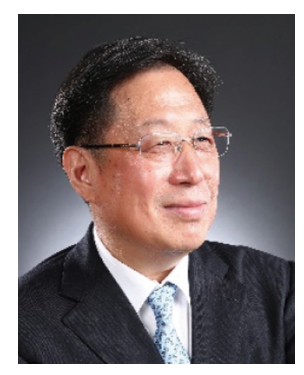

Jianguo Xu, Ph D.

Academician, Chinese Academy of Engineering

President, Chinese Pest Control Association

Director, State Key Laboratory of Infectious Disease Prevention and Control

Professor, National Institute for Communicable Disease Control and Prevention, China CDC 